\title{
Perceived inter-parental conflict and aggression among adolescents: Moderating role of optimism and pessimism
}

\author{
Muhammad Kamran Chaudhry ${ }^{*}$; Fakiha Shabbir ${ }^{2}$ \\ ${ }^{1}$ Foundation University, Rawalpindi Pakistan \\ ${ }^{2}$ Quaid e Azam University, Islamabad Pakistan
}

\author{
*Corresponding Author(s): Muhammad Kamran \\ Chaudhry \\ Department of Psychology, Foundation University, \\ Rawalpindi Pakistan \\ Email: ch.kamran@outlook.com
}

Received: Aug 21, 2018

Accepted: Nov 09, 2018

Published Online: Nov 14, 2018

Journal: Journal of Psychiatry and Behavioral Sciences

Publisher: MedDocs Publishers LLC

Online edition: http://meddocsonline.org/

Copyright: (C) Chaudhry KM (2018). This Article is distributed under the terms of Creative Commons Attribution 4.0 International License

Keywords: Aggression; Optimism; Pessimism; Adolescents

\begin{abstract}
Objective: The present study aimed to explore the moderating role of optimism and pessimism on the relationship of perceived inter-parental conflict and aggression among adolescents. Adolescents are distinct group to study, as they are free from societal pressures to act in certain ways. Thus, present study is planned to study the role of optimism-pessimism in adolescent's personality how this orientation contributes in perceiving inter-parental conflict. Differences regarding demographic variables like gender are also explored on inter-parental conflict, aggression and optimism-pessimism.
\end{abstract}

Method: The sample included 372 Adolescents with age range of $14-15$ years studying in Grade 10 from various model schools of Islamabad. The sample of study was selected by using convenient sampling technique. The sample comprised 186 male students and 186 female students meeting the above-mentioned criteria. The sample of 372 grade 10 students was selected by using G*Power Calculater [1]. The participants responded on demographic sheet investigating their personal information such as gender, age, family system, The Children's Perception of Inter-parental Conflict Scale (CPIC), Aggression Scale (AS) and The Youth Life Orientation Test (YLOT).

Results: After data collection all, the instruments were scored, coded and entered in the Statistical Package for Social Sciences (SPSS) version 20.0. To find out relationship between children Inter-parental conflict, aggression and pessimism-optimism Pearson's product moment correlation was used. Multiple regressions was used to test prediction of child's Inter-parental conflict towards aggression and pessimism-optimism. For testing gender differences on the three variables t-test was used.

Conclusion: The above discussion of the results suggests that inter-parental conflict, pessimism and aggression are positively correlated while inter-parental conflict and optimism are negatively correlated. Furthermore, it was found

Cite this article: Chaudhry KM, Shabbir F. Perceived inter-parental conflict and aggression among adolescents: moderating role of optimism and pessimism. J Psychiatry Behav Sci. 2018: 4: 1016. 
that inter-parental conflict is strong predictor of aggression and pessimism among adolescents. The results also indicate that females have slightly high rates of inter parental conflict than males. On the other side, males have high rates of aggression and optimism than females. Pessimism has no significant difference among males and females. The results further describes that individuals from nuclear family system have slightly high rates of inter-parental conflict and optimism than individuals from joint family system. On the other side, the individuals from joint family system have slightly high rates of aggression and pessimism than individuals from nuclear family system.

\section{Introduction}

The family atmosphere shared by parents and children is influenced by several forces, but perceived inter-parental conflict is mostly significant. Inter-parental relationship is the basis of the family therefore; it can have major effect on the family environment. It can have negative effect on the family environment and behavior of adolescent's. Adolescents are more likely to show internalizing behaviors when compared with younger children while perceiving inter-parental conflict. However, certain dispositional traits of children such as orientation towards life (pessimistic and optimistic) might change the situation. The present study aimed to explore the moderating role of optimism and pessimism and the relationship of perceived inter-parental conflict and aggression among adolescents.

Inter-parental conflict has several dimensions including frequency, interval, intensity, and mode of expression and the level of resolution all of which are significant importance in considering the impact of inter-parental conflict. Age range of adolescence is from 10 to 19 years. Adolescents are cognitively more mature and developed than younger children. This insight and involvement of adolescents in inter-parental conflict may positively or negatively affect them depending on the stance that individual has toward life. This may result in the adolescents experiencing externalizing (e.g., misbehavior, delinquency, aggression) or internalizing behaviors (e.g., depression, anxiety) or increased healthy behaviors and styles [2].

Exposure to inter-parental conflict is a prevalent source of stress for children. Inter-parental conflict has been identified as a major source of behavior problems in children. In a study conducted by Shaw [3] he concluded that inter-parental conflict and behavior problems are positively correlated. An examination of specific aspects of conflict may tell us how much and what kind of conflict is most detrimental to the members of the family. Although the amount of conflict has been shown to affect adjustment of children, how conflict is resolved may also play an essential role.

Children of parents who experience conflicts in their relationship later show more aggressive acts in their life and usually have disruptive relationships. The largest reason of this is that parents become less and less concerned about their child well- being and more concerned with their family patterns [4]. Research thus indicates that children's perceptions and beliefs about inter-parental violence are important for shaping the impact of these family interactions [5].

Sana [6] conducted study on Perceived Inter-Parental Conflicts and Family Functioning as Predictor of Adjustment Problems in Late Adolescence and found significant positive correla- tion among inter parental conflict and adjustment problems like anger, antisocial behavior and emotional distress. Kim et al., [7] also found that adolescent who witness inter-parental conflict in homes are more likely to experience relational and sexual aggression, verbal, emotional and physical abuse and hostile behaviors. Study conducted by Fear [8] on children of depressed parents: inter-parental conflict, blaming self and coping. The findings suggested that high inter-parental conflict is strongly correlated to children's anxious and aggressive behavior problems. They also found significant evidence that the more children think themselves responsible for inter-parental conflict the more emotional and behavior problems they report. It means the more pessimistically child thinks about inter-parental conflict the more he become depressed and aggressive. Barthassat [9] studied effects of inter-parental conflict on children and concluded that positive and negative effects depend upon the positive or negative attitude of parent. He suggested that children's emotional effects are subjected to type of conflict between parents.

A study about marital conflict, parenting and attachment styles concluded that marital conflict lead to poor self-esteem and behavior problem whereas parental warmth tend to increase self-esteem and reduce behavior problems. Two main models are used to clarify the relation between inter-parental conflict and child's adjustment, which are direct effect model and indirect effect model [10]. Indirect effects model suggest that marital conflict may influence other family, parental, and parent-child relationship factors, which subsequently influence child adjustment. Direct effects models posit that marital conflict increases children's vulnerability to poor psychological adjustment by increasing children's distress and reactivity to conflict.

\section{Inter-parental Conflict}

Inter-parental conflict is defined as expression of negative affect between parents [11]. Inter-parental conflict is a term that represents a continuum of parental behaviors ranging from verbal disagreements to physical violence. Inter-parental conflict has negative effects on home environment and adolescent behavior [12]. According to social modeling, adolescent watch and replicate their parent's behavior to modify their conflictive behavior [13]. According to attachment theory, parental conflict can cause child maladjustment because of insecure parent-child relationship. By watching, how parents deal each other during conflict is likely to have negative consequences for children's in their social interactions. Inter-parental conflicts have an effect on various aspects of life including adjustment, self -concept, love relationships, social capability and thoughts about marriage in adolescent's life. Reese-Weber and Kahn [14] has suggested that adolescents watch their parent's conflict behavior and the way it is resolved and then practice similar behaviors with siblings, and partners.

Researchers have emphasized the importance of children's perception of and reactions to, inter-parental conflict. The interpretations that children make out of inter-parental conflict verify whether the conflict is upsetting to them and causing trouble in their adjustments. How children's perceive inter parental conflict affects their psychological distress. Grych and Fincham [12] proposed that children's perceptions and the way they interpret inter-parental conflict play significant role in exploring the effect that marital conflict has on children's emotional and behavioral adjustment. Children who see conflict as threatening 
and feel incapable to cope well are likely to go through feelings of helplessness and anxiety when conflict occurs, and children who held themselves responsible for parental conflict experience shame, guilt and grief.

Children can develop difficulties when conflict between parents is handled destructively. Destructive conflict includes: physical or verbal aggression; sulking or the 'silent treatment'; getting caught up in highly intense or heated arguments and withdrawing or walking away from an argument. Many factors contribute to child's insecurities of their parents arguments such as when they or issues relevant to them are the subject of an argument or are less troubled by conflict when parents are able to resolve an argument [11].

Latest research by Elemary, Omari and Wynaden [15] on adolescent's perceptions of inter-parental conflict found that adolescents witnessing inter-parental conflict are likely to feel sad, scared and emotionally charged and are unable to stop thinking about conflict they have witnessed earlier. Moreover, adolescents also reported negative psychosocial consequences, which expose them to sense of insecurity that may place them at risk of internalizing and externalizing problems. Researchers have concluded that those children have higher levels of stressrelated urinary hormones that come from families where parents are in conflict and also have lower levels of psychological coping resources or less-effective coping styles [16]. Studies suggest that parental conflict is associated with an increase in child's aversive behavior because parents become absorbed in their own conflicts and are less consistent or effective in their children's discipline practices.

Sana [6] conducted study on Perceived Inter-Parental Conflicts and Family Functioning as Predictor of Adjustment Problems in Late Adolescence and found significant positive correlation among inter parental conflict and adjustment problems like anger, antisocial behavior and emotional distress. Kim et al., also found that adolescent who witness inter-parental conflict in homes are more likely to experience relational and sexual aggression, verbal, emotional and physical abuse and hostile behaviors.

\section{Theories of inter-parental conflict}

\section{Cognitive-contextual model}

The cognitive-contextual model was proposed by Grych and Fincham in 1993. This model explains the relation between inter-parental conflict and child internalizing and externalizing behaviors. In short, the cognitive-contextual model states that children are affected by inter-parental conflict depending on their interpretations made about the conflict. This model explains the four characteristics of inter parental conflict that may affect child including incidence, strength, content and decree which are explained in the later section. They also proposed that the way adolescent perceive and evaluate the family conflict might have significant effect on their behavior. According to this model after witnessing inter-parental conflict, the children try to find out the reason that leads to conflict. How adolescents perceive the inter-parental conflict predicts their externalizing and internalizing behaviors. Moreover, internalizing behaviors are mostly determined by how the conflict is being resolved by the parents.

\section{Triangulation model}

The triangulation model explains the effects of children's in- volvement in inter-parental conflict. This model suggests that when parents include child into inter-parental conflict, they are at more risk for developing behavioral consequences. In triangulation, the parents don not attack each other directly they instead use child for indirect attack. This indirect attack could be in any form, messages, or sharing sensitive or private information about conflict in order to get support or empathy from child. The children then are at more risk of behavior problems and can blame themselves for the ongoing conflicts. Fosco and Grych [5] studied adolescent triangulation into parental conflict and concluded that triangulation or involvement of children into inter-parental conflict can lead to strong feelings of selfblame in children and it could reduce the quality of relationship between child and parent.

\section{Emotional security hypothesis}

Patrick Davies and Mark Cummings [11] proposed the emotional security hypothesis to analyze the effects of parental conflict on children. Children's feelings of insecurity is hypothesized to be a function of three regulatory systems such as emotional reactivity and arousal, interpretations of the meaning and the potential consequences of the conflict for one's own well-being and level of involvement in or withdrawal from conflict.

\section{Dimensions of inter parental conflict}

Different dimensions of conflict are recognized as important to child outcomes, including frequency, intensity, content, resolution style, and tactics of conflict.

\section{Frequency}

Researchers have suggested that there exist a relationship between the frequency of inter parental conflict and child outcomes [12]. Frequency refers to how frequently parents get involved in conflict with each other regarding family issues. Frequent inter parental conflict makes children more sensitized to future conflicts. Research conducted by Kerig [17] examining the relationship between inter-parental conflict and child adjustment found that frequency of inter-parental conflict has significant correlation with child's internalizing and externalizing symptoms.

\section{Intensity}

Intensity is another important factor in Inter-parental conflict that varies from minor disagreements to fierce physical aggression. Studies have suggested that children show more negative response to conflicts with physical aggression than other level of conflict [18].

\section{Content}

Content of disagreements or topics of conflict is also important factor in understanding inter parental conflict and its effects on children. Research has revealed that clashes or arguments between parents about children's related topics have more negative impacts on child development. Study conducted on role of topic and style of inter parental conflict on child coping. The children's of age 12 to 13 were shown conflict videos involving different conflict tactics. It was found that children's reported that they will interfere more in inter parental conflict if it involves physical aggression or verbal anger in conflicts related to child issues [19].

\section{Resolution Style}

Another factor in inter parental conflict and child outcomes 
is resolution style. Children's are greatly influenced by the degree to which conflicts are resolved successfully. Resolved conflicts are those that end with apology or compromise while unresolved conflicts are those that end with when parents stop talking to each other. Resolved conflict is perceived by children as less negative event as compared to unresolved conflict [20]. It shows that prior exposure to resolved conflict leave children with positive expectations about outcomes of conflict in future. Unresolved conflicts can cause pessimistic future expectations and can cause emotional distress in children.

\section{Correlates of inter-parental conflict}

\section{Inter-parental conflict and aggression}

Aggression is defined as behavior that creates tender and painful experience to others, or as acts that are vicious to one's self, others or things. Aggression is defined as act, which is impulsive and unprompted. Aggression is noticeable behavior, which can collapse, hurt, threaten or impair a person or destroy an object. It is not planned occurring majorly during times of stress, fatigue or frustration. Aggression is any behavior that delivers on noxious stimulus to another person. Aggression is any act that is planned to injure the target. A general definition of aggression is a behavioral act that could hurt or harm to another person [21].

It is difficult to define aggression, as people use this term to explain a large variety of actions, for example, to hurt others, forceful dealing with others, assertiveness etc.,. Aggressive behavior towards nonliving objects is the outcome of frustration. Aggression is any kind of act planned to harm or hurt other person and the victims avoids those actions targeted toward him. It does not include accidental acts that can cause harm or hurt others. The behaviors or actions that cause bodily or physical injury to others are aggressive acts of aggression. Human intensions behind are complex to understand. Aggressive acts produce noxious stimulus to another organism and emphasis is on the consequences of the aggressive acts rather than the intensions [22]. Breakwell [23] stated that people commit aggression with ease but find the term too complex to define for all fields of study.

\section{Theories of aggression}

Aggression is defined from different aspects, such as a learned response to frustration as biological based behaviour. Aggression has been explained from different perspectives.

\section{Social learning theory}

Social learning theory explains aggression as a learned form of social behaviour which takes place either through experiences or observation. It is acquired in the same way like other social behaviours [24]. This theory explains roots of aggression stemming from past experiences or many situational factors. The social learning theory suggests that children learn aggressive characteristics such as when how and against whom to show aggression from their environment. They learn aggression by observing parents, from their peer groups and friends and from different forms of media that present different forms of aggression and violence.

\section{Cognitive neo association theory}

Research has suggested that factors such as provocation, loud noise, unpleasant odors, frustration and disturbing temperature produce negative affect. These negative affect trig- gered through negative experiences automatically stimulates responses and reactions which are linked with fighting tendencies. Cognitive neo association theory suggest that cues present during aversive event become associated with event and then trigger emotional or cognitive response related to it. According to this theory aggressive emotion, thoughts and behaviors are interlinked in memory. The way a person interprets negative emotions will regulate his response. If the unpleasant emotional experiences are inferred as anger then the aggressive tendencies are likely to take place. Berkowitz also explained that aggressive cues are not in fact necessary for the aggression. Rather, these cues intensify the aggression which occurs as a result of hurdles in goal attainment [25].

\section{Frustration-aggression Theory}

This theory focus on external cues, which explains that "aggression is always an outcome of frustration" and "frustration always results some type of aggression". According to this theory, the tendency to show aggression increases as the rate of frustration increases. Dollard and his companions defined frustration as an "interference with the behavior sequence", it may be concluded as one will be frustrated if he/she is unable to have what he/she want when he/she want it. This theory states that higher the frustration, the higher the tendency of aggression will exist as a result. Frustration-aggression theory suggests two sources through which an individual can reduce the ability to aggress after one has been frustrated. First, frustration can be vanished or eliminated by discouraging the aggressive behavior. Second, the person may be given permission to display aggression [26].

\section{Types of aggression}

Types of aggression are given below:

\section{Physical aggression}

Physical aggression is referred to any act that can harm others by the use of weapons or by bare hands for the sake of lowering others or having control on others, elaborated combating and physical attack of privacy [27]. Anger is a recurrent mean of aggression; it may also be caused by intoxication or frustration.

\section{Relational aggression}

Relational aggression is defined as any act that is targeted to hurt someone in terms of relationships. Relational aggression is any behavior that is likely to harm anyone by damaging his/ her relationships with others. Relational aggression is founded to be linked with the higher degree of internal problems like depression [28].

\section{Hostile aggression}

Hostile aggression may also be called as anger and affective aggression. Hostile aggression is an aggressive act that is displayed to damage or injure the other person. The aim of hostile aggression is to pain and hurt someone. Reactive which is also known as affective aggression is an impulsive and negative response to threat or provocation, with the object of harming provoking person. Reactive aggression involves highly emotional arousal and is manifested in self-defensive and hostile manner. On the other hand, proactive, also known as instrumental aggression is controlled, more planned and occurs with forethought [22]. 


\section{Instrumental aggression}

Instrumental aggression is the type of aggression against another person in which aggression is expressed to attain some reward or achieve a goal. In other words, it can be stated as a form of aggression used to attain an object or gain a status or possession in a certain group. Learning theorists formulated this type of aggression. Instrumental aggression includes the individual's perception about probable rewards. It is also called Proactive aggression is directed at achieving specific rewards, like obtaining goods, seeking power or attaining peer approval. This type of aggression is manifested through bullying and coercive actions against weaker peers [29].

Many factors have been associated with aggression. Adolescent's life experiences are associated with aggression. Factors associated with childhood family, like poor parenting practices and lack of affection from parents increases probability of aggression. Adolescents observing aggressive and abusive behaviour of parents or significant adults are likely to behave aggressively. Moreover, low socio-economic status, parental misconduct and parental care free or encouraging attitudes towards violence are factors associated to aggressive acts. Evidence has suggested that inter parental conflict can negatively affect children's development. According to social learning theory perspective children who witness inter parental conflict at home may learn to apply same behavior in their own lives [24].

Social learning concept also suggests that exposure to inter parental conflict make children vulnerable to recognize violence as acceptable norm in society, which in turn increase their aggressive behavior. Several studies have proved that after witnessing conflict at home children are more likely to display aggression. Children after witnessing inter-parental conflict start to believe that aggression is suitable and efficient way of dealing with conflict and as a result they become willing to use violence themselves [5].

Additionally, inter-parental conflict can range from daily minor disagreements to more aggressive verbal and physical argument. Marital verbal aggression refers to insults and threats between parents. Marital physical violence involves physical harm to a partner and represents the extreme form of parental conflict. Children who witness intense anger and physical violence between parents are at a greater risk for externalizing behavior than children who witness verbal disagreements [12]. Youth aggression resulting from exposure to inter-parental conflict may be displayed within different types of interpersonal relationships. For example, several studies have demonstrated that inter-parental violence is associated with children's levels of peer conflict and with violent behavior in youth's own romantic relationships.

\section{Inter-parental conflict and optimism-pessimism}

Optimism is defined as personality attribute that includes emotional, motivational and cognitive constructs leading optimists to think and feel positively about the future [30]. Research has suggested that optimistic people expect positive outcomes in life and pessimistic people expect negative outcomes in life [31]. Optimism is the positive expectation of tendency to believe that good outcomes will occur in life. Positive expectation directs people to increase effort to achieve their goals for desired outcomes, whereas negative expectancies reduce effort to pursue goals. Optimism has been associated with successful coping skills and positive health outcomes by many researchers
[32].

Oxford Dictionary has defined optimism as an inclination towards hopefulness and confidence with the theory that good must eventually prevail over evil. Optimism is delightful view of future making person look forward to better, goodness and triumph. On the other hand, pessimism is a negative expectation of events making person expect vilest things to take place and anticipating negativity, failure and dissatisfaction. Optimism is an aspiration that something good will take place and a belief that positivity will overshadow the negativity. Researcher proposed that to some extent optimism is inherent in individuals but environmental factors play a significant role. Optimism has been defined as a mood or attitude associated with anticipation about the social or material future which is thought as desirable, beneficial and pleasurable for person [33].

Pessimism is tendency to expect negative future outcomes. Pessimistic people expect that they will be unsuccessful in achieving their goals, and therefore they discontinue their efforts to pursue their goals. Pessimists are timid and uncertain about various life challenges. Pessimists experience negative emotions, like anger, sadness, anxiety and despair during different life challenges. In short, they adopt avoidance and withdrawal strategies. Optimism has been associated with decreased psychological maladjustment and pessimism with increased psychological maladjustment. Several studies have shown that optimism, depression, physical atmosphere, anger, psychological well-being and anxiety all are interrelated. The more people are optimistic the more psychologically and physically healthier they are [31]

Puskar et at., [34] studied relationship between adolescent optimism, depression, coping skills, aggression and life events using measure of Life orientation test and self -report measures and concluded that those adolescents who were more optimistic were less likely to have symptoms of depression, less avoidant coping styles, few negative life events and low levels of aggression.

Gilham et al., [33] explained three types of optimism; explanatory optimism, strategic optimism and dispositional optimism. Explanatory optimism is psychological construct that propose that when people experience any particular event, positive or negative how they explain it to themselves. Explanatory style consists of three dimensions including personal, permanent and pervasive. Personal aspect includes internal versus external, explains the degree to which the person attributes event to an internal cause or self. An optimist will attribute negative event to luck whereas a pessimist might attribute it to self. An optimist would define his traits as stable while pessimist would define his traits as unstable. Pervasive aspect includes global versus local extent of effect. Global versus specific refers to whether or not a person's explanation generalizes the event to others beyond the specific event in hand. People who blame themselves for negative events believe that such events will persist for an indefinite period and allow such events to influence many aspects of their lives known as pessimistic explanatory style. In contrast, people who blame external factors for negative events believe that those events will end soon and don't allow such events to influence various aspects of their lives known as optimistic explanatory style.

Dispositional optimism is more relatable to stance in life that good things happen more to humans than bad things. As a personality trait, it is presumed to be stable with little scope 
for change and is alternatively described as big optimism [30] Research has associated dispositional optimism with desirable outcomes and effective coping. Research has suggested that optimism have moderating effect on how people deal with novel or challenging and difficult situations. In difficult times optimists tend to have positive emotional reactions and expectations. They expect positive outcomes with confident attitude and assume that adversity can be effectively handled in one way or another by using active and problem-focused coping strategies rather than avoidance. On other hand pessimist see themselves as doubtful and are hesitant during difficult situations and likely to anticipate disaster under adverse conditions [31].

\section{Inter-parental conflict and demographic factors}

Demographic factors such as sex, age and socioeconomic status are also correlated with inter-parental conflict. Gender differences have been identified in children's cognitive, behavioral and emotional reactions to inter parental conflict. [17] viewed this from cognitive perspective girls are more likely to blame the cause of their parent's conflict to themselves as compared to boys. Boys are more anxious with threat that they recognize to their security when their parents engage in conflict.

Evidence suggests that boys are more sensitive than girls to parental conflict and show more aggression [20]. Researchers suggest that girls are emotionally more aware than boys. It is also found the presence of gender differences while investigating cognitive emotion regulation. Furthermore, a Meta-analysis of gender differences in temperament indicates that boys show more inappropriate behavioral responses as compared to girls. Girls report better emotional awareness and small difficulty in controlling their behaviors when any negative event occurs in their life [35].

This is consistent with findings of Hotton [36] suggesting that boys showed higher levels of aggression as compared to girls. The responses of children to marital conflict tend to differ along gendered lines. Boys have been found to react to adult anger with aggression and anger, whereas girls tend to exhibit distress. Boys have also been found to be more likely to propose task-oriented interventions for parental conflict than girls, whereas girls are more likely to react to marital conflict with fear than are boys [10].

\section{Significance of the study}

The present study aims to find impact of inter-parental conflict on child's perception and aggression and the role of optimism-pessimism as mediating factor. Theoretical evidence suggests the role of inter-parental conflict in behavior and adjustment problems in children. The present study considers how optimism-pessimism can contribute in child's perception of inter-parental conflict and behavior problems like aggression. Theory and research clearly provide evidence that inter parental conflict has negative effects on home environment and adolescent behavior [12].

The present study aimed to explore the moderating role of optimism and pessimism on the relationship of perceived interparental conflict and aggression among adolescents. Adolescents are distinct group to study as they are free from societal pressures to act in certain ways. Thus, present study is planned to study the role of optimism-pessimism in adolescent's personality how this orientation contributes in perceiving interparental conflict. It has been adequately established through literature that inter-parental conflict is positively correlated to aggression among adolescents. However, the role of optimismpessimism in inter-parental conflict has been studied barely and gap in literature exists concerning its impact on children's perceptions of inter-parental conflict.

Differences regarding demographic variables like gender are also explored on inter-parental conflict, aggression and optimism-pessimism. It would be predicted in accordance of prevalent studies that boys are more sensitive to inter-parental conflict and have greater levels of optimism and aggression. Hence, adolescents perception of Inter-parental conflict escort to greater level of aggression which is more or less a proven fact. But the role of optimism-pessimism with regards to above two variables has been explored less and present study aims to demean its effects and consequences.

Method

\section{Objectives of the present study}

Following objectives are presented for the present study:

1. To explore the relationship between perceived interparental conflict and aggression among adolescents.

2. To study the relationship of pessimism and optimism with aggression among adolescents.

3. To determine the moderating role of optimism and pessimism with perceived inter-parental conflict and aggression among adolescents.

4. To investigate the impact of demographic variables on perceived inter-parental conflict, aggression, optimism and pessimism.

\section{Significance of the study}

This study will be helpful for parents to understand the effect of Inter-parental conflict on their children in terms of frequency, intensity and content. It will be insightful for them to understand the perceptions of their children and its impact on them. This may assist parents as well as siblings how to guide the young child now to control over aggression. It will also explore the role of optimism in personality of their children. This study also tries to find out role of optimism and pessimism in child's behavior resulting from Inter-parental conflict.

A parental conflict is seen as discrepancy causing greater or lesser interaction of the parents. Parents involved in conflict are likely to have undesirable interactions with their children, leading to behavior problems like aggression in children. This study will explore how child optimism and pessimism is related to Inter-parental conflict. Low optimism and greater pessimism can affect child's behavior negatively. Exposure to Inter-parental conflict is a big source of stress for children. The primary focus of this research is concerned with children's perception of Inter-parental conflict because such conflict severely affects children's psychological well-being. The sample of 14-15 age children was chosen because adolescence is the critical period for the development of healthy behaviors and life styles and Inter-parental conflicts have marked impact on children's behaviors till this age. Different studies suggest that to give training to the parents how to resolve the clashes through different strategies as well as encourage them to inculcate optimism in their life can decrease negative impacts (pessimism) on personality of their children. 


\section{Hypotheses of the Study}

Following hypothesis are formulated for the study

1. There will be positive relationship between perceived inter-parental conflict, pessimism and aggression.

2. There will be a positive relationship pessimism and aggression.

3. The will be a negative relationship between optimism and aggression.

4. Optimism and pessimism will interact with perceived inter-parental conflict to predict aggression among adolescent.

5. Demographic variables such as gender, socio-economic status, and parent's education predict perceived inter-parental conflict, aggression, optimism and pessimism.

\section{Research design}

Research design of the study will be co relational. The relationship and prediction of child's perception of Inter-parental conflict with aggression and pessimism-optimism was studied. It was hypothesized that greater perception of Inter-parental conflict results in greater aggression if optimism was high and vice versa. Data would be gathered from 600 grade 10 children of Islamabad by using instruments for the three variables. Informed consents would be obtained from different participants and there information would then be analyzed by using various statistical techniques.

\section{Population}

The population of the present study will comprise of all the students of Grade 10 in Islamabad. According to an estimate, the total number of grade 10 adolescents of Islamabad Schools is 13,240 .

\section{Sample}

Due to constraints of time and resources, sample will be selected as under:

- $\quad$ Sample would include 372 Adolescents between 14-15 years studying in Grade 10 from various model schools of Islamabad.

- $\quad$ The sample of study will be selected by using convenient sampling technique.

- $\quad$ The sample would include 186 male students and 186 female students meeting the above mentioned criteria.

- $\quad$ The sample of 372 grade 10 students was selected by using $\mathrm{G} *$ Power Calculater [1].

\section{Operational definitions of study variables}

\section{Children perception of inter-parental conflict}

It includes perception of child about conflict between parents and affecting child's life in terms of many areas of conflict and personality [37].

\section{Children aggression}

The term aggression refers to number of components that lead to harmful consequences for others. These may include verbal physical and emotional anger towards others [38].

\section{Optimism-pessimism}

Optimism is described as a set of beliefs about the forthcoming life, generally referred to as optimism and anticipations about bad outcomes is referred to as pessimism [39].

\section{Research tools}

\section{Following instruments will be used to conduct the study:}

Demographic Sheet: The demographic sheet was formed to investigate various demographic variables including gender, age, educational level, birth order, family system, and number of siblings and parent's level of education.

Children Perception of Inter-parental Conflict Scale (CPIC) [37]: The Children's Perception of Inter-parental Conflict Scale (CPIC) was developed by Grych, Seid and Fincham in 1992. This measure is widely used by researchers examining inter-parental conflict and its consequence on children's personality. It consists of 51 statements that are organized into nine subscales namely Frequency, Intensity, Resolution, Threat, Coping Efficacy, Content, Self -Blame, Triangulation, and Stability. The subjects have to show their response on three point rating scale. The CPIC alpha reliabilities on nine subscales range from 0.61 to 0.83 . The scores range from 51 to 153 with the higher scores depicting greater perception of child's Inter-parental conflict.

Aggression Sscale (AS) [38]: The Aggression Scale includes 11 items and was developed by Orpinas and Frankowski in 2001. The scale measures behaviors that may cause emotional or bodily injury to other students. Although the directions used in instrument do not specify the location of these acts but largely the scale taps aggression against other students. Questions are limited to explicit display of violent actionsResponses to each item range from 0 times through 6 or more times. Thus, the aggression score range between 0 and 66 points. The alpha reliability of scale was reported to be .88 .

Youth Life Orientation Test (Y-LOT) [39]: The Youth Life Orientation Test (YLOT) developed by Eye et al. was used to assess optimism-pessimism dimensions of child's personality. Children are asked to rate how accurate the responses are for them on a four point scale. The measure is composed of 6 items assessing optimism, 6 items assessing pessimism and 2 filler items Specifically, children were asked to respond by coloring in the circle describes them to be the best'. The YLOT was intended to produce three scores: an optimism score, a pessimism score, and a total optimism score. The sub-scales are each scored and advanced score indicates greater level of the three constructs. The reliabilities of three sub-scales were reported to range between .75 to .80 .

\section{Data collection}

Informed consent was obtained from participants. Data was collected from children personally through questionnaire.

\section{Data analysis}

After data collection all the instruments were scored, coded and entered in the Statistical Package for Social Sciences (SPSS) version 20.0. To find out relationship between children Interparental conflict, aggression and pessimism-optimism Pearson's product moment correlation was used. Multiple regressions was used to test prediction of child's Inter-parental conflict towards aggression and pessimism-optimism. For testing gender differences on the three variables t-test was used. 


\section{Results}

The results of the table 1 show that all instruments i.e., Children's Perception of Inter-Parental Conflict Scale, Aggression Scale and Youth Life Orientation Scale have high alpha coefficient reliabilities. The reliability for Children's Perception of Inter-Parental Conflict Scale is .64; Aggression Scale is .81 and Youth Life Orientation Scale is .66. These values indicate moderate reliabilities.

Table 2 characterizes the division of total sample on the basis of gender, family system and job. The age ranges of sample are 14-18 years. As the table shows, gender distribution of sample is equal i.e., females (50.0\%) and males (50.0\%). Approximately $60 \%$ of the participants belonged to nuclear family system and $40 \%$ to joint family system.

Table 3 illustrates the results of correlation between Children's Perception of Inter-Parental Conflict Scale, Aggression Scale and Youth Life Orientation Scale among adolescents. The results show significant positive correlation which proves the hypothesis that there is a correlation between aggression, optimism-pessimism and inter-parental conflict among adolescents. The results also show significant positive correlation between aggression and pessimism and significant negative correlation between aggression and optimism, which supports hypothesis that there is a correlation between aggression and optimismpessimism among adolescents.

Table 4 shows regression analysis to study the predictive value of pessimism-optimism and Inter-parental conflict on aggression. The table depicts that Inter parental conflict $(\beta=0.63$, $t=5.72, p<.01)$ and Optimism- Pessimism $(\beta=0.58, t=5.91, p<$ 0.01 ) are significant predictors of aggression in adolescents. The value of R2 shows that $46 \%$ of variance is accounted for in aggression by both pessimism-optimism and Inter-parental conflict. The above stated prediction is significant at $F(13.78)$ and $p<0.01$.

Graph A represents the predictive value of pessimism and Inter-parental conflict on aggression. According to the description, the graph clearly shows that high rates of aggression and inter-parental conflict indicate high levels of pessimism whereas low rates of aggression and inter-parental conflict indicate low levels of pessimism.

This graph represents the predictive value of optimism and Inter-parental conflict on aggression. According to the description, the graph clearly shows that low rates of aggression and inter-parental conflict indicate high levels of optimism whereas high rates of aggression and inter-parental conflict indicate low levels of optimism.

Table 5 shows difference between males and females in terms of Children's perception of Inter-parental conflict, Optimism and Pessimism on level of aggression. The results indicate that females have slightly high rates of inter parental conflict than males. On the other side, males have high rates of aggression and optimism than females. Pessimism has no significant difference among males and females.

Table 6 shows difference between nuclear and joint family systems in terms of Children's perception of Inter-parental conflict, Optimism and Pessimism on level of aggression. The results indicate that individuals from nuclear family system have slightly high rates of inter-parental conflict and optimism than individuals from joint family system. On the other side, the individuals from joint family system have slightly high rates of aggression and pessimism than individuals from nuclear family system.

\section{Discussion}

Conflicts are observed as regular part of family life. Inter parental conflict is defined as expression of negative affect between parents. Inter-parental conflict is an important predictor of adolescent's behavioral and emotional adjustment problems. Inter-parental conflicts have an effect on various aspects of life including adjustment, self concept, love relationships, social capability and thoughts about marriage in adolescent's life. Recent researches have focused on factors that play role in inter-parental conflict and the impact of those factors on adolescents. Certain sets of dispositions like aggression and optimism-pessimism have been studied as prominent factors in predicting inter-parental conflict.

The present study was conducted to study impact of interparental conflict on adolescents' perception and aggression and role of optimism-pessimism as mediating factor. All scales reliabilities were found to be satisfactory (Table 1 ). The result analysis showed significant positive relationship between interparental conflict, aggression and optimism-pessimism. It also describes positive correlation between aggression and pessimism and negative correlation between aggression and optimism (Table 3). Thus, this finding was found to be consistent with that of Jamil [40] who conducted correlational study on perceived inter-parental conflict and aggression and findings revealed that significant positive correlation exist between perceived inter-parental conflict and aggression in adolescents.

[8] also found significant positive correlation and concluded that the more pessimistically child thinks about inter-parental conflict the more he become depressed and aggressive. Similarly, it was seen in another study that there exists positive correlation between inter-parental conflict and children's aggression. It was also found that optimism act as mediator in relationship between parental conflict and children adjustment [41].

Previous research findings have by and large supported the idea that aggression was strongly correlated with inter-parental conflict. Results of present study also revealed that there exists significant positive correlation between aggression, pessimism and inter-parental conflict (Table 4 and graphs $A$ and $B$ ). Research also showed parental conflict also cause aggressive symptoms which in turn produce behavior problems in children. Large number of evidence in literature support these findings too. Many studies have revealed that exposure to violence in home has strong significant relationship with aggressive behavior among adolescents [36].

As far as optimism-pessimism is concerned, its relationship with inter-parental conflict has been studied by handful of studies. Research has suggested that parental warmth and support can lead to positive and healthy interactions in children whereas negative parenting leads to negative or pessimistic outcomes in children [42]. Researchers also suggested that children witnessing inter-parental conflict expressed low optimism toward expectations of family relationships and are more pessimistic. They also concluded that higher levels of inter-parental conflicts witnessed by adolescents were associated with low levels of optimism.

The optimism-pessimism has also been linked with aggression. The findings of present study suggest that significant posi- 
tive correlation between aggression and pessimism and sig nificant negative correlation between aggression and optimism (Table 4 and graphs A\&B). Thus, this finding was also found to be consistent with that of [36] who concluded that there exist a significant positive relationship between pessimism and aggression. Similarly it was also found in another study that there exists a significant negative relationship between optimism and aggression [34].

It was also hypothesized that demographic factors such as gender, socioeconomic status and family system predict perceived inter-parental conflict, aggression and optimism-pessimism.

Table 5 shows difference between males and females in terms of Children's perception of Inter-parental conflict, Optimism and Pessimism on level of aggression. The results indicate that females have slightly high rates of inter parental conflict than males. On the other side, males have high rates of aggression and optimism than females. Pessimism has no significant difference among males and females. It would be predicted in accordance of prevalent studies that boys are more sensitive to inter-parental conflict and have greater levels of optimism and aggression. Hence, adolescents perception of Inter-parental conflict escort to greater level of aggression which is more or less a proven fact. But the role of optimism-pessimism with regards to above two variables has been explored less and present study aims to demean its effects and consequences.

Table 6 shows difference between nuclear and joint family systems in terms of Children's perception of Inter-parental conflict, Optimism and Pessimism on level of aggression. The results indicate that individuals from nuclear family system have slightly high rates of inter-parental conflict and optimism than individuals from joint family system. On the other side, the individuals from joint family system have slightly high rates of Graphs

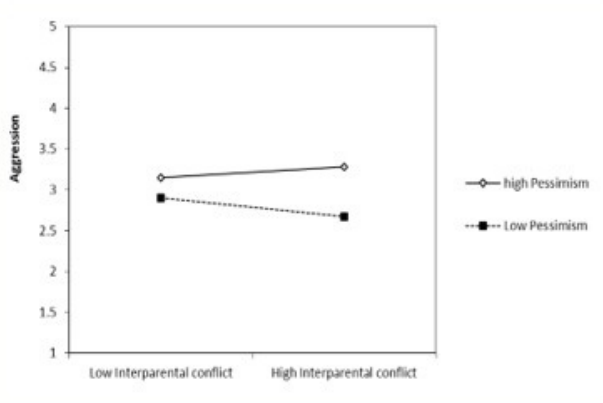

Graph A: predictive value of pessimism and Inter-parental conflict on aggression aggression and pessimism than individuals from nuclear family system. Theory and research clearly provide evidence that inter parental conflict has negative effects on home environment and adolescent behavior [12].

\section{Limitations}

\section{The study has following limitations:}

1. The sample of the study was limited to Islamabad only, which limits the research to generalize findings.

2. The other limitation of the study is that the measures used in present study were self- reported. Self report measures can be problematic because even though participants are aware of confidentiality and anonymity, there is a potential for the desire to appear in a favorable lights therefore, participants may be motivated to respond in ways that are not completely truthful.

\section{Conclusion}

The above discussion of the results suggests that inter-parental conflict, pessimism and aggression are positively correlated while inter-parental conflict and optimism are negatively correlated. Furthermore, it was found that inter-parental conflict is strong predictor of aggression and pessimism among adolescents. The results also indicate that females have slightly high rates of inter parental conflict than males. On the other side, males have high rates of aggression and optimism than females. Pessimism has no significant difference among males and females. The results further describes that individuals from nuclear family system have slightly high rates of inter-parental conflict and optimism than individuals from joint family system. On the other side, the individuals from joint family system have slightly high rates of aggression and pessimism than individuals from nuclear family system.

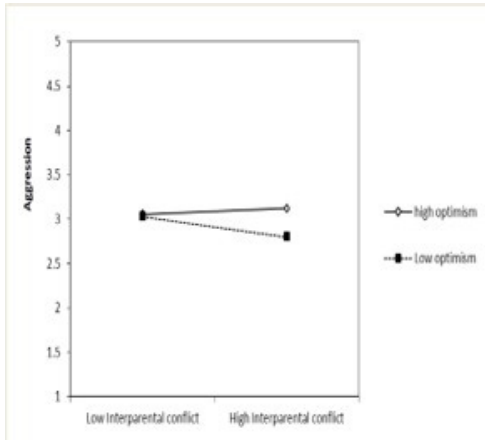

Graph B: predictive value of optimism and Inter-parental conflict on aggression

Tables

Table 1: Alpha Reliability, Mean, Standard deviation, Skewness and Kurtosis of Inter-parental Conflict Battery, Aggression Scale and Youth Life Orientation Scale ( $\mathrm{N}=372)$.

\begin{tabular}{|c|c|c|c|c|c|c|c|c|}
\hline Scales & $\mathbf{N}$ & $\alpha$ & Mean & Std. dev & $\begin{array}{c}\text { Skewnes } \\
95 \% \mathrm{Cl}\end{array}$ & & $\begin{array}{c}\text { Kurtosis } \\
\mathbf{9 5 \%}\end{array}$ \\
\hline CPIC & 51 & 1 & 116 & 13.5 & Statistics & Std. error & Statistics & Std. error \\
\hline AGG & 29 & 1 & 89 & 16.2 & 0.43 & 0.126 & -0.086 & 0.252 \\
\hline YLOT & 19 & 1 & 40 & 6.5 & 0.62 & 0.126 & -0.106 & 0.252 \\
\hline
\end{tabular}

Note: CPIC: Children's Perception of Inter-parental Conflict Scale; AGG: Aggression Scale: YLOT= Youth Life Orientation Test. 
Table 2: Demographic description of the Sample $(\mathrm{N}=372)$.

\begin{tabular}{|l|c|c|}
\hline \multicolumn{1}{|c|}{ Demographic variables } & Frequency & Percentage \\
\hline Gender & & \\
\hline Males & 186 & 50 \\
\hline Females & 186 & 50 \\
\hline Family System & 149 & \\
\hline Joint & 223 & 40 \\
\hline Nuclear & & 60 \\
\hline Job & 186 & 50 \\
\hline Government & 186 & 50 \\
\hline Private & \\
\hline
\end{tabular}

Table 4: Multiple Regression to study the impact of Children's perception of Interparental conflict and pessimism-optimism on level of aggression ( $\mathrm{N}=372$ ).

\begin{tabular}{|c|c|c|}
\hline \multirow{2}{*}{} & \multicolumn{2}{|c|}{ Aggression } \\
\hline Variables & & Model 1 \\
\hline Constant & B & $95 \% \mathrm{Cl}$ \\
\hline Inter Parental conflict & 0.6 .5 & {$[66.71,77.22]$} \\
\hline Optimism-Pessimism & 0.58 & {$[0.05,0.89]$} \\
\hline R2 & \multicolumn{2}{|c|}{0.46} \\
\hline F & \multicolumn{2}{|c|}{13.78} \\
\hline
\end{tabular}

Table 3: Correlation matrix of Inter-parental Conflict Battery, Aggression Scale and Youth Life Orientation Scale ( $N=372$ ).

\begin{tabular}{|c|c|c|c|c|c|}
\hline S.No. & Scales & $\mathbf{1}$ & $\mathbf{2}$ & A & B \\
\hline I & $\begin{array}{c}\text { Inter-parental } \\
\text { Conflict }\end{array}$ & 1 & $.04^{* *}$ & $-.07^{* *}$ & 0.15 \\
\hline II & Aggression & & 1 & $-.08^{* *}$ & $.22^{* *}$ \\
\hline III & $\begin{array}{c}\text { Youth Life Orienta- } \\
\text { tion }\end{array}$ & & & & \\
\hline A & Optimism & & & 1 & $-.23^{* *}$ \\
\hline B & Pessimism & & & & 1 \\
\hline
\end{tabular}

Note: CPIC: Children's Perception of Inter-parental Conflict Scale; AGG: Aggression Scale: YLOT: Youth Life Orientation Test** $p<0.01$.

Note: Cl: Confidence Interval.

Table 5: Difference between Males ( $n 185)$ and Females ( $n=187)$ in terms of Children's perception of Inter-parental conflict, Optimism and Pessimism on level of aggression ( $\mathrm{N}=372$ ).

\begin{tabular}{|c|c|c|c|c|c|c|c|c|c|c|}
\hline \multicolumn{10}{|c|}{ GENDER } \\
\hline & \multicolumn{9}{|c|}{ Males $n=185$} & \multicolumn{2}{|c|}{ Females $n=187$} & & & & \multicolumn{2}{|c|}{$95 \% \mathrm{Cl}$} & \\
\hline Scales & $\mathrm{M}$ & $\mathrm{SD}$ & $\mathrm{M}$ & $\mathrm{SD}$ & $\mathrm{t}$ & $\mathrm{df}$ & $\mathrm{p}$ & $\mathrm{LL}$ & $\mathrm{UL}$ & $\begin{array}{c}\text { Lev- } \\
\text { en's t }\end{array}$ \\
\hline CPIC & 115 & 14.0 & 118 & 12.9 & -1.9 & 370 & .00 & -5.4 & .06 & .863 \\
\hline AGG & 90.4 & 17.2 & 87.5 & 15.1 & -1.7 & 370 & .00 & -6.2 & .38 & 3.48 \\
\hline Optimism & 8.6 & 3.0 & 8.5 & 2.5 & .67 & 370 & .00 & -.45 & .70 & .298 \\
\hline Pessimism & 15.9 & 3.9 & 15.8 & 3.5 & .85 & 370 & .00 & -.69 & .83 & 3.38 \\
\hline
\end{tabular}

Note: CPIC: Children's Perception of Inter-parental Conflict Scale; AGG: Aggression Scale.

Table 6: Difference between nuclear $(n=223)$ and joint $(n=149)$ family systems in terms of Children's perception of Inter-parental conflict, Optimism and Pessimism on level of aggression ( $N=400)$.

\begin{tabular}{|c|c|c|c|c|c|c|c|c|c|c|}
\hline \multicolumn{10}{|c|}{ FAMILY SYSTEM } \\
\hline & \multicolumn{2}{|c|}{ Nuclear } & \multicolumn{2}{|c|}{ Females $n=187$} & & & & \multicolumn{2}{|c|}{$95 \% \mathrm{Cl}$} & \\
\hline $\mathrm{n}=223$ & Joint & SD & M & SD & $\mathrm{t}$ & $\mathrm{df}$ & $\mathrm{p}$ & $\mathrm{LL}$ & $\mathrm{UL}$ & Leven's t \\
\hline $\mathrm{n}=149$ & & & & $95 \% \mathrm{Cl}$ & & 370 & .00 & -5.4 & .06 & .863 \\
\hline Scales & $\mathrm{M}$ & $\mathrm{SD}$ & $\mathrm{M}$ & $\mathrm{SD}$ & $\mathrm{t}$ & $\mathrm{df}$ & $\mathrm{p}$ & $\mathrm{LL}$ & $\mathrm{UL}$ & Leven's t \\
\hline CPIC & 117 & 13.8 & 115.8 & 13.0 & 1.35 & 370 & .00 & -.87 & 4.7 & .498 \\
\hline AGG & 88.9 & 13.2 & 89.0 & 19.9 & -.06 & 370 & .00 & -3.4 & 3.2 & 29.5 \\
\hline
\end{tabular}




\begin{tabular}{|c|c|c|c|c|c|c|c|c|c|c|}
\hline Optimism & 8.7 & 2.8 & 8.4 & 2.8 & .95 & 370 & .00 & -.30 & .87 & .996 \\
\hline Pessimism & 15.5 & 3.8 & 16.2 & 3.5 & -1.6 & 370 & .00 & -1.4 & .10 & 3.85 \\
\hline
\end{tabular}

Note: CPIC: Children's perception of Inter-parental Conflict Scale; AGG = Aggression Scale.

\section{References}

1. Buchner A, Faul F. How to use G*Power [Computer manual]. 2007.

2. Scheier MF, Carver CS, Bridges MW. Optimism, pessimism, and psychological well-being. EC Chang, editors. In: Optimism and pessimism: Implications for theory, research, and practice. Washington, DC: American Psychological Associatio. 2001: 189216.

3. Daniel S Shaw. Behavior Modification. 1991; 15: 456-485.

4. Erel O, Burman B. Interrelatedness of marital relations and parent-child relations: a meta-analytic review. Psychol Bull. 1995; 118: 108-132.

5. Fosco GM, Grych JH. Emotional expression in the family as a context for children's appraisals of interparental conflict. 2007.

6. Sana. Perceived Inter-Parental Conflicts and Family Functioning as Predictor of Adjustment Problems in Late Adolescence. Institute of Applied Psychology. University of the Punjab, Pakistan. 2013.

7. Kim. Adolescent Report of Interparental Conflict: The Role of Threat and Self-blame Appraisal on Adaptive Outcome. Journal of Child and Family Studies. 2008; 17: 735-751.

8. Fear M Jessica. Children of Depressed Parents: Interparental Conflict, Self-Blame, and Coping. Nashville, Tennessee. 2007.

9. Barthassat J. Positive and Negative Effects of Parental Conflicts on Children's Condition and Behaviour. Journal of European psychology students. 2014; 5: 10-18.

10. Davies PT. Delineating the sequelae of destructive and constructive interparental conflict for children within an evolutionary framework. Developmental Psychology. 2012; 48: 939-955.

11. Cummings EM, Davies PT. Maternal depression and child development. Journal of Child Psychology \& Psychiatry. 1994; 35: 73112.

12. John H Grych, Finchman F. Children's Appraisals of Marital Conflict: Initial Investigations of the Cognitive-Contextual Framework. Child Development. 1993; 215-230.

13. Pryor JE, Pattison R. Adolescents' perceptions of parental conflict: The downside of silence. Journal of Family Studies. 2007; 13: 72-77.

14. Reese-Weber M, Kahn JH. Familial predictors of sibling and romantic-partner conflict resolution: comparing late adolescents from intact and divorced families. Journal of Adolescents. 2005; 28: 479-493.

15. Elemary F, Al Omari O, Wynaden D. The perception of adolescents' inter-parental conflict and accompanied emotional security: A descriptive study. Journal of Nursing Education and Practice. 2016; 6: 84-90.

16. Gottman JM, Katz L. Effects of marital discord on young children's peer interaction and health. Developmental Psychology. 1989; 25: 373-381.

17. Kerig PK. Assessing the links between interparental conflict and child adjustment: The conflicts and problem-solving scales. Journal of Family Psychology. 1996; 10: 454-473.
18. Laumakis MA, Margolin G, John RS. The emotional, cognitive, and coping responses of preadolescent children to different dimensions of marital conflict. GW Holden, R Geffner, EN jouriles, editors. In: Children 1 exposed to marital conf1ict: Theory, research, and applied issues. Washington, DC: American Psychological Association. 1998.

19. Shelton K, Harold GT. Cognitive appraisals and coping strategies psychological adjustment: Bridging links through children's pathways between interparental conflict and adolescent psychological adjustment. Journal of Early Adolescence. 2008; 28: 555-582.

20. El-Sheikh M, Cummings EM, Kouros CD, Elmore-Staton L, Buckhalt J. Marital psychological and physical aggression and children's mental and physical health: direct, mediated, and moderated effects. Journal of Consulting and Clinical Psychology. 2008; 76: 138-148.

21. Pettit GS. Reactive and proactive aggression in school children and psychiatrically impaired chronically assaultive youth. J Abnorm Psychol. 1997; 106: 37-51.

22. Buss AH. The psychology of aggression. New York: Wiley 307 Department of Psychology, University of Pittsburgh, Pittsburgh, PA. 1961.

23. Breakwell GM. Coping with Aggressive Behaviour. (Personal and Professional Development). Leicester, UK. BPS Blackwell. 1997.

24. Bandura A. Social cognitive theory: An agentic perspective. Annual Reviews Psychology. 2001; 52: 1-20.

25. Berkowitz Leonard. Frustration-aggression hypothesis: Examination and reformulation. Psychological Bulletin. 1989; 106: 5973.

26. Dollard J, Doob L, Miller N, Mowrer O, Sears R. Frustration and aggression. New Haven, CT: Yale University Press. 1939.

27. Greenberg BS, Edison N, Korzenny F, Fernanadez-Collado C, Atkin CK. Antisocial and prosocial behaviors on television. In B. S. Greenberg (Ed.), Living with television: Content analyses of US. TV drama. 1980; 99-128.

28. Nicki R. Crick and Jennifer K. Grotpeter. Relational Aggression, Gender, and Social-Psychological Adjustment Child Development. Published by: Wiley on behalf of the Society for Research in Child Development. 1995; 66: 710-722.

29. Geen RG, Donnerstein E. Human Aggression: Theories, Research, and Implications for Social Policy. San Diego: Academic Press. This book is a general introduction to several topics of current interest in aggression research written by authorities in each area. 2001.

30. Peterson C. The future of optimism. Am Psychol. 2000; 55: 4455.

31. Michael SF, Carver Charles. Optimism, coping, and health: Assessment and implications of generalized outcome expectancies. Health psychology : official journal of the Division of Health Psychology, American Psychological Association. 1985; 4: 219247.

32. Taylor SE, Kemeny ME, Reed GM, Bower JE, Gruenewald TL. Psychological resources, positive illusions, and health. Am Psychol. 2000; 55: 99-109. 
33. Gillham Jane, Reivich Karen. Cultivating Optimism in Childhood and Adolescence. Annals of the American Academy of Political and Social Science - Ann Amer Acad Polit Soc Sci. 2002; 591: 146-163.

34. Kathryn R Puskar, Susan M Sereika, Jacqueline Lamb, Kathleen Tusaie-Mumford, Teena Mcguinness Optimism And Its Relationship To Depression, Coping, Anger, And Life Events In Rural Adolescents, Issues in Mental Health Nursing. 1999; 20: 115-130.

35. Butt Sanam Gulzar \& Yahya. Cognitive Emotional Regulation and Forgiveness. University Utara Malaysia, Sintok, Malaysia. 2013.

36. Tinna Hotton. Childhood Aggression and Exposure to Violence in the Home. Crime and Justice Research Paper Series, No. 002, Canadian Centre for Justice Statistics. 2003.

37. Grych JH, Seid M, Fincham FD. Assessing marital conflict from the child's perspective: The Children's Perception of Interparental Conflict Scale. Child Development. 1992; 63: 558-572.

38. Orpinas Pamela, Frankowski Ralph. The aggression scale: A self report measure of aggressive behavior for young adolscents. J Early Adolesc. 2001; 21: 51-68.
39. Eye S, Hadley W, Allen DN, Palmer S, Klosky J, Deptula D, et al. A new measure of children's optimism and pessimism: the youth life orientation test. J Child Psychol Psychiatry. 2005; 46: 548558.

40. Jamil Farah. Interparental Conflict and Aggression in Adolescents. Institute of Applied Psychology. University of the Punjab, Pakistan. 2012.

41. Robinson. Distinguishing optimism from pessimism in older adults: Is it more important to be optimistic or not to be pessimistic? Journal of Personality and Social Psychology. 1997; 73:1345-1353.

42. Roy AB, Brian B, Crane D. Parental Support, Behavioral Control, and Psychological Control Among African American YouthThe Relationships to Academic Grades, Delinquency, and Depression. Journal of Family Issues - J FAM ISS. 2006; 27: 1335-1355. 